\title{
Penerapan Fintech Dengan Aplikasi Ovo Sebagai Digital Payment Bagi Ibu - Ibu PKK RT 02/ RW 04 Di Dukuhwaluh Purwokerto
}

\author{
Oryz Agnu Dian Wulandari ${ }^{1}$, Siti Barokah ${ }^{2}$, Nadila Al Azhar ${ }^{3}$, Habib Al Ghazali ${ }^{4}$ \\ email: ${ }^{2}$ oryzdian@amikompurwokerto.ac.id, ${ }^{2}$ siti.barokah@amikompurwokerto.ac.id, \\ 3nadillaala@gmail.com, 4bibghazali@gmail.com
}

\begin{abstract}
Abstrak
Digital payment atau pembayaran secara digital merupakan teknologi yang saat ini berkembang pesat di era industri 4.0 serta merupakan pandangan baru bagi masyarakat dalam melakukan pembayaran non-tunai yang jauh lebih praktis, sistematis dan aman dalam melakukan segala kegiatan transaksi. Sebagian orang mengetahui digital payment adalah uang elektronik yang dapat digunakan dalam melakukan pembayaran dalam berbagai transaksi. Ibu- ibu PKK RT02/RW04 di desa Dukuhwaluh Purwokerto selama ini masih menggunakan pembayaran secara tunai, oleh karena itu perlu adanya pengetahuan serta keterampilan mengenai digital payment dengan aplikasi yang telah berkembang pada saat ini sebagai pendukung adanya teknologi dalam digital payment yakni OVO. Adapun tujuan dari pengabdian kepada masyarakat ini adalah memberikan pengetahuan serta keterampilan kepada Ibu- ibu PKK RT02/RW04 di desa Dukuhwaluh Purwokerto Ibu- ibu PKK RT02/RW04 di desa dukuhwaluh Purwokerto Ibu- ibu PKK RT02/RW04 di desa Dukuhwaluh Purwokerto dengan memanfaatkan aplikasi digital payment OVO. Pengetahuan dan pelatihan yang dibutuhkan adalah bagaimana cara memiliki aplikasi OVO, membuat akun OVO dan bagaimana cara menggunakan aplikasi OVO serta segala keunggulan dari aplikasi OVO sebagai alat pembayaran non-tunai. Metode yang digunakan dalam kegiatan pengabdian ini ialah memberikan materi presentasi dan cara penggunaan aplikasi OVO. Kegiatan awal yang dilakukan adalah melakukan survey tempat, melaksanakan program yang telah dirancang serta melakukan monitoring dan evaluasi program. Tahap persiapan awal dilakukan melalui kerjasama dengan pengurus PKK RT02/RW04 di desa Dukuhwaluh untuk melaksanakan survey tempat serta memperoleh informasi dari pengurus PKK mengenai permasalahan yang dihadapi masyarakat sekitar dalam mengikuti perkembangan zaman di era industri 4.0 ini. Pelaksanaan program yang telah dirancang yaitu dilakukan dengan cara memberikan informasi serta pelatihan kepada masyarakat sekitar mengenai OVO dan penggunaannya. Capaian dari kegiatan pengabdian masyarakat ini adalah terlaksananya bentuk pelatihan dalam memanfaatkan aplikasi OVO dengan jumlah peserta 18 orang yang dapat mengikuti pelatihan sampai akhir acara dan peserta memperoleh pengetahuan untuk dapat memanfaatkan aplikasi OVO yang dapat meningkatkan keterampilan Ibu - ibu anggota PKK di RT02 /RW04 di desa Dukuhwaluh Purwokerto dalam mamanfaatkan OVO sebagai digital payment.
\end{abstract}

Kata Kunci : Digital Payment, OVO, Pengetahuan, Pelatihan. 


\begin{abstract}
Digital payment or digital payment is a technology that is currently developing rapidly in the industrial era 4.0 and is a new perspective for the public in making non-cash payments that are far more practical, systematic and safe in carrying out all transaction activities. Some people know that digital payments are electronic money that can be used to make payments in various transactions. PKK RT02 / RW04 women in the village of Dukuhwaluh Purwokerto have been using cash payments, therefore it is necessary to have knowledge and skills regarding digital payment with applications that have developed at this time to support the existence of technology in digital payment, namely OVO. The purpose of this community service is to provide knowledge and skills to PKK RT02 / RW04 mothers in Dukuhwaluh Purwokerto village PKK RT02 / RW04 mothers in dukuhwaluh Purwokerto village PKK RT02 / RW04 mothers in Dukuhwaluh Purwokerto village by utilizing digital applications payment OVO. The knowledge and training needed is how to have the OVO application, create an OVO account and how to use the OVO application and all the advantages of the OVO application as a non-cash payment tool. The method used in this service activity is to provide presentation material and how to use the OVO application. Initial activities carried out are conducting site surveys, implementing programs that have been designed and monitoring and evaluating programs. The initial preparation stage was carried out in collaboration with the PKK RT02 / RW04 administrators in the village of Dukuhwaluh to carry out a site survey and obtain information from PKK administrators regarding problems faced by the surrounding community in keeping up with the times in this industrial era 4.0. The implementation of the program that has been designed is done by providing information and training to the surrounding community regarding $O V O$ and its use. The achievement of this community service activity is the implementation of a form of training in utilizing the OVO application with 18 participants who can take part in the training until the end of the event and participants gain knowledge to be able to take advantage of the OVO application which can improve the skills of PKK members in RT02 / RW04 in the village Dukuhwaluh Purwokerto in using $\mathrm{OVO}$ as a digital payment.
\end{abstract}

Keywords: Digital Payment, OVO, Knowledge, Training.

\title{
Pendahuluan
}

Perkembangan teknologi di Indonesia saat ini berkembang pesat dalam proses mencari informasi maupun dalam melakukan komunikasi. Perkembangan tersebut juga didukung dengan teknologi yang muncul dari meningkatnya penggunaan mobile phone berbasis android yang mampu mengakses berbagai aplikasi - aplikasi yang dapat membantu berkembangnya teknologi dalam memenuhi kebutuhan sehari - sehari serta memudahkan dalam melakukan transaksi. Kemudahan dalam bertransaksi merupakan salah satu kemajuan dari berkembangnya teknologi, salah satunya adalah dalam melakukan sistem pambayaran secara elektronik yang dikenal dengan electronic money. Perubahan uang sangat pesat mengikuti perkembangan teknologi, baik kertas maupun logam dengan electronic money (Adiyanti, 2015). Berkembangnya electronic money menjadi alternatif yang baik saat ini dalam melakukan pembayaran non tunai serta memiliki berbagai manfaat dan keuntungan. 
Pembayaran dengan e-money akan memberikan kemudahan bagi masyarakat Indonesia dalam melakukan transaksi secara online dengan efektif dan efisien. (Suryani, Kurniawan, \& Umiyati, 2020), e-money adalah aplikasi menyimpan uang yang digunakan sebagai alat transaksi dengan menggunakan metode mobile payment. Menurut (Nielsen, 2016), Industri mobile payment saat ini berkembang sangat pesat. Layanan e-money yang saat ini telah dikenal masyarakat membutuhkan proses yang panjang agar dapat diterima oleh masyarakat umum. (Parastiti, Mukhlis, \& Haryono, 2015), menyatakan bahwa e-money memiliki tujuan untuk mengurangi pertumbuhan penggunaan uang tunai. Perkembangan transaksi secara online menunjukan peningkatan secara signifikan dari tahun ke tahun yang dapat mempengaruhi aplikasi mobile payment seperti aplikasi OVO yang merupakan teknologi informasi dalam bidang digital payment. (Usman, 2017), menyatakan bahwa pembayaran non tunai pembayaran yang dilakukan secara non tunai tidak hanya dengan menggunakan kartu melainkan dengan smartphone. OVO adalah aplikasi digital payment yang memiliki berbagai manfaat bagi masyarakat dalam kehidupan seharihari untuk melakukan transaksi pembayaran serta dapat memberikan kemudahan bagi para penggunanya. (Sagayarani, 2018), menyatakan bahwa pembayaran secara digital merupakan cara melakukan pembayaran melalui mode digital. Fiture yang ditawarkan OVO juga dapat membantu dalam mengatur pengeluaran dalam sebulan bagi penggunanya selain itu OVO juga menjadi aplikasi dompet virtual untuk menyimpan uang yang dapat digunakan untuk membayar atau bertransaksi sesuai dengan yang dibutuhkan.

Ibu - Ibu PKK RT02/RW04 di desa Dukuhwaluh Purwokerto banyak yang belum mengerti mengenai aplikasi OVO sebagai digital payment dalam melakukan transaksi, selama ini dalam melakukan pembayaran masih secara tunai. (Librianty, 2016), mengatakan bahwa kendala lain yang dialami yakni masih belum terbukanya masyarakat untuk menggunakan uang elektronik (e-money) dikarenakan masih terbiasa menggunakan uang tunai atau membudayanya uang tunai serta belum mengetahui efisiensi yang diberikan dari e-money. Menurut (Arner, Barberis, \& Buckley, 2015), berpendapat bahwa fintech dapat memberikan solusi keuangan dan merupakan salah satu aspek perubahan. Selain itu menurut (Chrismastianto, 2017), fintech adalah inovasi financial yang mengacu pada teknologi modern. Inovasi tersebut memiliki tujuan memperkenalkan kemudahan, kenyamanan biaya ekonomis, (D'Alimonte et al., 2014). Melihat kondisi tersebut, kami memberikan pengetahuan dan pelatihan mengenai OVO serta bagaimana cara menggunakan dan mengaplikasikan OVO dalam melakukan transaksi pembayaran. Capaian dari kegiatan pengabdian masyarakat ini adalah terlaksananya bentuk pelatihan dalam memanfaatkan aplikasi OVO dengan jumlah peserta 18 orang yang dapat mengikuti pelatihan sampai akhir acara dan peserta memperoleh pengetahuan untuk dapat memanfaatkan aplikasi OVO yang dapat meningkatkan keterampilan anggota PKK di RT02 /RW04 di desa Dukuhwaluh Purwokerto dalam mamanfaatkan OVO sebagai digital payment. 


\section{Metode}

Metode dalam melaksanakan kegiatan pengabdian kepada masyarakat adalah dengan cara memberikan informasi serta pelatihan kepada Ibu- ibu PKK RT02/RW 04 desa Dukuhawaluh mengenai aplikasi OVO serta kegunaannya. Metode kegiatan pelatihan ini dilakukan berdasarkan pendekatan proses pembelajaran teori dan pembelajaran praktek (Gata, Imelda, Yuliazmi, \& Siswanto, 2020). Kegiatan awal yang dilakukan adalah melakukan survey tempat, melaksanakan program yang telah dirancang serta melakukan monitoring dan evaluasi program. Tahap persiapan awal dilakukan melalui kerjasama dengan pengurus PKK RT02/RW04 di desa Dukuhwaluh untuk melaksanakan survey tempat serta memperoleh informasi dari pengurus PKK mengenai permasalahan yang dihadapi masyarakat sekitar dalam mengikuti perkembangan zaman di era industri 4.0 ini. Pelaksanaan program yang telah dirancang yaitu dilakukan dengan cara memberikan informasi serta pelatihan kepada masyarakat sekitar mengenai OVO dan penggunaannya. Proses pelaksanaan program meliputi:

1. Memberikan Infromasi kepada Ibu - ibu PKK RT02/RW04 mengenai aplikasi OVO dan penggunaannya.

2. Mendownload serta membuat akun OVO pada mobile phone.

3. Mengenalkan fitur yang ditawarkan OVO serta memberikan pelatihan bagaimana penggunaanya.

4. Memberikan pelatihan bagaimana cara mengisi saldo OVO dan bagaimana memperoleh POINT pada aplikasi OVO.

Kegiatan mamantau dan mengevaluasi dilakukan dengan tujuan melihat seberapa berhasil program yang telah dilaksanakan. Evaluasi dilakukan dengan mengamati hasil pelatihan oleh si penerima materi. Kegiatan yang dilakukan ini diharapkan dapat memberikan manfaat bagi Ibu - ibu PKK RT02/RW04 di Desa Dukuhwuluh dalam menggunakan e-money untuk melaksanakan transaksi secara digital payment yang saat ini telah berkembang di Indonesia.

\section{Hasil dan Pembahasan}

Hasil yang telah diperoleh selama melaksanakan pengabdian dengan cara memberikan informasi tentang OVO serta pelatihan penggunaan OVO kepada Ibu ibu PKK RT02/RW04 guna memberikan pengetahuan mengenai e-money sebagai digital payment adalah :

1. Meningkatnya pengetahuan serta pemahaman ibu - ibu PKK RT02/RW04 di Desa Dukuhwaluh tentang aplikasi OVO serta penggunaannya.

2. Memberikan pengetahuan bagaimana memiliki akun OVO dan pengisian Saldo serta kegunaan point pada OVO.

3. Kemampuan ibu -ibu PKK dalam memahami fitur OVO serta penggunaan OVO sebagai digital payment.

Kegiatan pengabdian ini melibatkan dua orang dosen dan dua orang mahasiswa yang memiliki keahlian pada bidang digital payment dengan aplikasi OVO dalam 
melaksanakan pengabdian ini. Kegiatan pelatihan dilakukan di salah satu rumah seorang warga RT02/RW 04 desa dukuhwaluh yang dilaksanakan pada hari jumat, 22 November 2019 dengan jumlah peserta 18 orang dari pukul 15.30 sampai dengan pukul 16.30 .

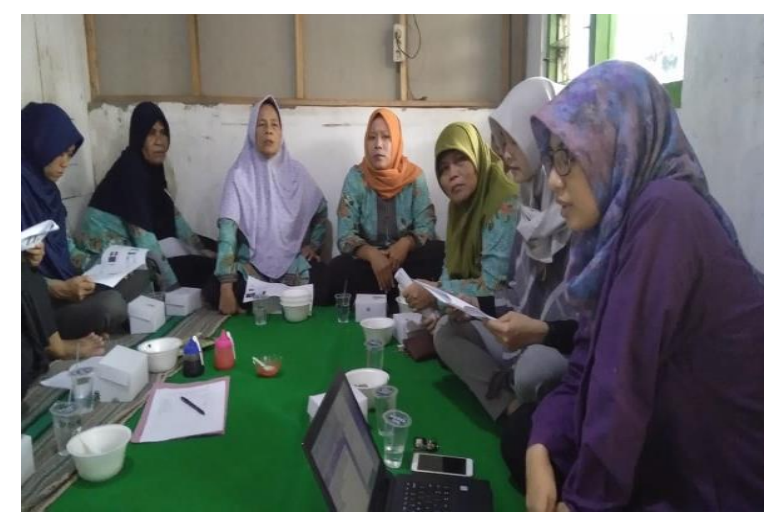

Gambar 1. Memberikan Informasi Mengenai Aplikasi OVO dan Penggunaannya

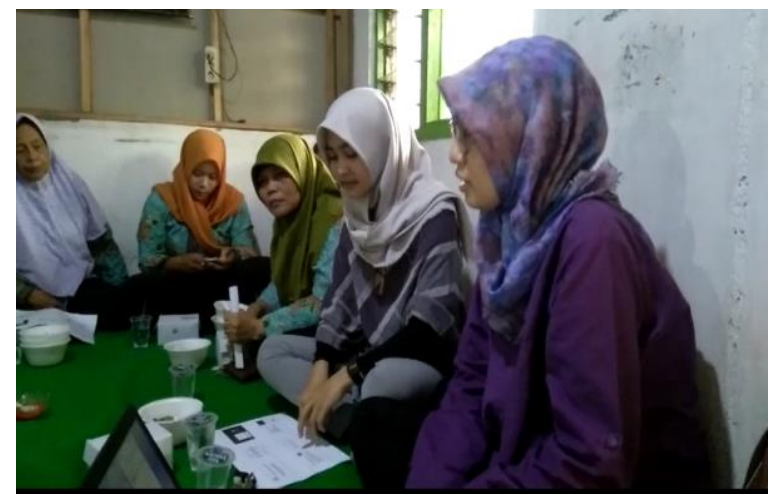

Gambar 2. Memberikan Pelatihan Penggunaan Aplikasi OVO

Dari hasil monitoring serta evaluasi yang dilakukan setelah melaksanakan pengabdian kepada 18 orang Ibu - ibu PKK adalah 95\% merasakan peningkatan pengetahuan serta informasi yang berkaitan dengan OVO, hal tersebut diketahui dari tingkat antusias ibu - ibu dalam menerima materi OVO serta banyaknya pertanyaan yang disampaikan ibu - ibu untuk mengetahui tentang aplikasi OVO, 90\% menyatakan senang memperoleh informasi mengenai teknologi yang berkembang saat ini agar Ibu - Ibu PKK dapat mengikuti perkembangan zaman dan tidak tertinggal dengan perkembangan teknologi di Indonesia.

\section{Simpulan dan Rekomendasi}

Dari hasil pengabdian ini dapat disimpulkan bahwa pengetahuan serta pelatihan dalam penggunaan aplikasi OVO dapat membantu masyarakat secara umum dan Ibu - ibu PKK khususnya untuk memanfaatkan aplikasi OVO sebagai aplikasi digital payment saat melakukan transaksi serta dengan fitur yang ada pada aplikasi OVO dapat membantu dalam mengatur pengeluaran selama 1 bulan setelah melakukan transaksi dengan aplikasi OVO. Saran atau rekomendasi pada kegiatan berikutnya ialah memperdalam penggunaan teknologi baik teknologi financial, marketing 
maupun online shop dengan marketplace yang telah berkembang, karena masih banyak ibu- ibu yang belum sadar akan perkembangan teknologi yang saat ini berkembang pesat di Indonesia.

\section{Daftar Pustaka}

Adiyanti, A. I. (2015). Pengaruh Pendapatan, Manfaat, Kemudahan Penggunaan, Daya Tarik Promosi, Dan Kepercayaan Terhadap Minat Menggunakan Layanan E-Money. Jurnal Ilmiah Akuntansi Dan Bisnis, 13, 1-13. Retrieved from https://jimfeb.ub.ac.id/index.php/jimfeb/article/view/1590

Arner, D. W., Barberis, J. N., \& Buckley, R. P. (2015). The Evolution of Fintech: A New Post-Crisis Paradigm? SSRN Electronic Journal. https://doi.org/10.2139/ssrn.2676553

Chrismastianto, I. A. W. (2017). Analisis SWOT Implementasi Teknologi Finansial Terhadap Kualitas Layanan Perbankan di Indonesia. Jurnal Ekonomi Dan Bisnis, 20(1), 133-144.

https://core.ac.uk/download/pdf/190864220.pdf

Retrieved from

D'Alimonte, L., Morton, G., Loblaw, A., Chung, H., Law, N., Ciseski, T., ... Zhang, L. (2014). Does Prostate Biopsy after HDR Brachytherapy Have Any Clinical Significance? Journal of Medical Imaging and Radiation Sciences, 45(2), 176-177. https://doi.org/10.1016/j.jmir.2014.03.053

Gata, G., Imelda, I., Yuliazmi, Y., \& Siswanto, S. (2020). Pelatihan Pengelolaan Blog Untuk Remaja Di RPTRA Manunggal Kelurahan Petukangan Selatan. Jurnal Abdimas BSI: Jurnal Pengabdian Kepada Masyarakat, 3(1), 39-44. https://doi.org/10.31294/jabdimas.v3i1.6706

Librianty, A. (2016). Tantangan Wujudkan Gerakan Nasional Non Tunai. pp. 1-5. Retrieved from https://www.liputan6.com/tekno/read/2609031/tantanganwujudkan-gerakan-nasional-non-tunai

Nielsen. (2016). Mobile Money: From shopping to banking to payments, how mobile is transforming commerce around the world. Global Mobile Money Report, (October), 01-27.

Parastiti, D. E. P., Mukhlis, M., \& Haryono, A. (2015). Analisis Penggunaan Uang Elektronik Pada Mahasiswa Fakultas Ekonomi Universitas Negeri Malang (Studi Kasus: Uang Elektronik Brizzi). Jurnal Ekonomi Dan Studi Pembangunan, 7(1), 7582.

Sagayarani, D. (2018). Digital Payments in India 2018-2019. ISOR Journal of Business Management(ISOR-JBM), 28-33.

Suryani, D., Kurniawan, A., \& Umiyati, I. (2020). IT Self Efficacy, IT Anxiety dan Minat Menggunakan E-money. Jurnal Riset Akuntansi Dan Keuangan, 8(1), 89-108. https://doi.org/10.17509/jrak.v8i1.20387

USMAN, R. (2017). Karakteristik Uang Elektronik Dalam Sistem Pembayaran. Yuridika, 32(1), 134. https://doi.org/10.20473/ydk.v32i1.4431 